\title{
Medium-density Fibreboard Milling Using Selected Technological Parameters
}

\author{
Grzegorz Pinkowski, * Waldemar Szymański, Magdalena Piernik, and Andrzej Krauss
}

The aim of this study was to investigate the effect of blade type and sharpness angle on blade wear, cutting power, and surface roughness. The study was conducted on medium-density fibreboard (MDF) panels. Two blade types were analyzed (high-speed steel and cemented carbides) along with three variants of sharpness angles $\left(40^{\circ}, 45^{\circ}\right.$, and $\left.55^{\circ}\right)$. Machining operations were performed on a spindle moulder at a feed rate of $6.3 \mathrm{~m} / \mathrm{min}$ and rotational speed of $4500 \mathrm{~min}^{-1}$. The blade wear criterion was adopted as the loss of cutter surface area measured on the rake face. Roughness was determined using the $R_{a}$ parameter, which was measured at three points on the cross-section of the MDF panel. A new, multifaceted approach to the study of cutting a narrow surface of the MDF board was used, thanks to which the interaction of such parameters as blade wear, cutting power, and machining quality as well as the type of material of the knives and their angular parameters were determined. An increase in blade wear and cutting power was recorded with an increase in cutting path, while roughness at the MDF panel cross-section varied. The cemented carbides cutter with the $45^{\circ}$ angle may be proposed as optimal, because it showed a relatively low wear and cutting power while providing good quality of the milled surface.

Keywords: MDF; Plane milling; Sharpness angle; Surface roughness; Wear; Cutting power

Contact information: Poznan University of Life Sciences, Department of Woodworking Machines and Fundamentals of Machine Design, Wojska Polskiego Str. 28, 60 -637 Poznan, Poland;

*Corresponding author: Grzegorz.Pinkowski@up.poznan.pl

\section{INTRODUCTION}

Lignocellulose materials used in the wood industry are characterised by a wide range of assortments and multiple applications. One of the most used materials in the furniture industry is a medium-density fibreboard (MDF) panel, which started to be commercially produced as early as the 1980s (Davim et al. 2009).

In terms of their machining, MDF panels have been investigated in several aspects. Deus et al. (2018), İşleyen and Karamanoğlu (2019), and Sütcü and Işleyan (2012) studied processes of face milling on wide surfaces based on pocket milling, i.e., milling to remove material to a certain depth to produce cavities or pockets, as in engraving, particularly when using the computer numerical control (CNC) milling machines. Sanding is another type of machining applied on extensive surfaces of MDF panels. Studies on that subject have been conducted by Hiziroglu et al. (2004) and Hiziroglu and Kosonkorn (2006). Machining of extensive surfaces of MDF panels is particularly common for foil or varnish/lacquer coatings. Another research aspect concerns milling of narrow panel surfaces. The MDF panels are often covered with various types of materials, like melamine laminates, to enhance their aesthetic value. When such panels are cut, it is essential to test the quality of the machining of the narrow panel surface based on various technological parameters 
(Aguilera et al. 2000; Davim et al. 2009; Zhong et al. 2013; Deus et al. 2015; Sedlecký 2017; Sedlecký and Kvietková 2017; Sedlecký et al. 2018a, 2018b). In addition, it is important to evaluate edge machining, i.e., identification of potential splinting or chipping (Souza et al. 2019).

Cutting MDF is first tested in terms of machining quality. However, this quality is affected by many factors, among which a major one is tool wear. Blade wear may cause problems with machining quality, which in turn is determined by numerous factors related both to the machined material itself and the adopted technological parameters or the selection of an appropriate tool.

There are several direct and indirect criteria, which facilitate determination and prediction of blade wear. This may be based on measurements of acoustic pressure (Aguilera et al. 2016a), energy consumption during cutting (Atanasov and Kovatchev 2019), and quality of the obtained surface (Aguilera et al. 2016b; Sedlecký 2017), but also through direct measurements of stereometry of the tool blade such as nose radius (Kazlauskas et al. 2019), retreat of wedge corner due to wear (Aguilera et al. 2016b), or wear area (Pinkowski et al. 2015).

Lignocellulosic materials, such as particleboards, MDF, and, plywood, which are commonly used in furniture manufacture, are more difficult to machine than solid wood. As a result of their greater density and contents of various components, including minerals, they result in increased blade wear.

Tool wear increasing with the cutting path on the one hand causes a deterioration of the quality of machined surfaces, while on the other hand it relates to an increased consumption of energy required in the cutting process.

Machining quality is most frequently determined based on selected parameters of surface roughness, typically amplitudinal in character. For wood-based materials, roughness may be determined using non-contact (optical) methods (Koleda et al. 2019; Stefanowski et al. 2020) as well as the more common contact method (Hiziroglu et al. 2004; Davim et al. 2009; Pinkowski et al. 2018), for the latter when applied to lignocellulose materials it is important for the gauge needle pressure to be as small as possible.

Among the many directions of research on MDF boards presented above, this paper presents research focused on the cutting of narrow surfaces.

The aim of this research was a comprehensive approach to the treatment of narrow MDF surfaces. In the research cited above, an approach was presented in which the impact of usually single aspects (parameters) on the cutting process of MDF boards was analyzed. A novelty in the presented research was the determination of many aspects of MDF board cutting and their interdependencies, i.e. knife wear, cutting power consumption and surface quality, as well as the type of material of the knives and their angular parameters.

\section{EXPERIMENTAL}

\section{Materials}

Cutting operations were performed on an MDF panel (Swiss Krono, Żary, Poland) of $16 \mathrm{~mm}$ in thickness. Density of the MDF panel at the cross-section varied, which affected roughness of the narrow surface. For this reason, roughness was measured at three points approximately $1 \mathrm{~mm}$ from the MDF panel edge on both sides of the panel and in its core. Density values of the MDF panel at measurement points are given in Table 1. 
Table 1. Density of the MDF Panel Depending on Surface Roughness Measurement Points

\begin{tabular}{|c|c|c|}
\hline Measuring Location & Symbol & $\begin{array}{c}\text { Density } \\
\left(\mathbf{k g} / \mathbf{m}^{3}\right)\end{array}$ \\
\hline Top & 1 & 750 \\
\hline Center & 2 & 680 \\
\hline Bottom & 3 & 730 \\
\hline
\end{tabular}

\section{Methods}

Cutting tests were performed using two cutter types (Gopol, Jarocin, Poland) made from high-speed steel (HS) and cutters with cemented carbide inserts (HW). From each type of blade material, three cutters were manufactured with various sharpness angles, i.e. $40^{\circ}, 45^{\circ}$, and $55^{\circ}$. Cutters were mounted in a 4-cutter cylinder milling head. Cutting operations were performed with one cutter.

Milling was performed on a Felder F900 spindle moulder (Felder, Hall in Tirol, Austria). Technological parameters adopted in the tests are given in Table 2.

Table 2. Technological Parameters Adopted in the Tests

\begin{tabular}{|c|c|c|c|}
\hline Parameter & Symbol & Value & Unit \\
\hline Rotational speed & $\mathrm{n}$ & 4500 & $\mathrm{~min}^{-1}$ \\
\hline Feed speed & $\mathrm{V}_{f}$ & 6.3 & $\mathrm{~m} / \mathrm{min}$ \\
\hline Cutting diameter & $\mathrm{D}$ & 104 & $\mathrm{~mm}$ \\
\hline Depth of cut & $\mathrm{h}$ & 2 & $\mathrm{~mm}$ \\
\hline Rake angle & $\gamma$ & 25 & ${ }^{\circ}$ \\
\hline Sharpness angle/clearance angle & & $40 / 25$ & \\
& & $45 / 20$ & $\circ$ \\
\hline
\end{tabular}

Blade wear was measured using a Carl Zeiss ME-10 contact profilometer (Carl Zeiss, Jena, Germany) with specialist measuring sensors.

The primary criterion for blade wear was the surface area of wear calculated between the cutter edge profiles: the sharp blade and after a specified cutting path. The profiles were established along the main cutting edge. The scheme of measurements for the blade wear surface area is presented in Fig. 1.

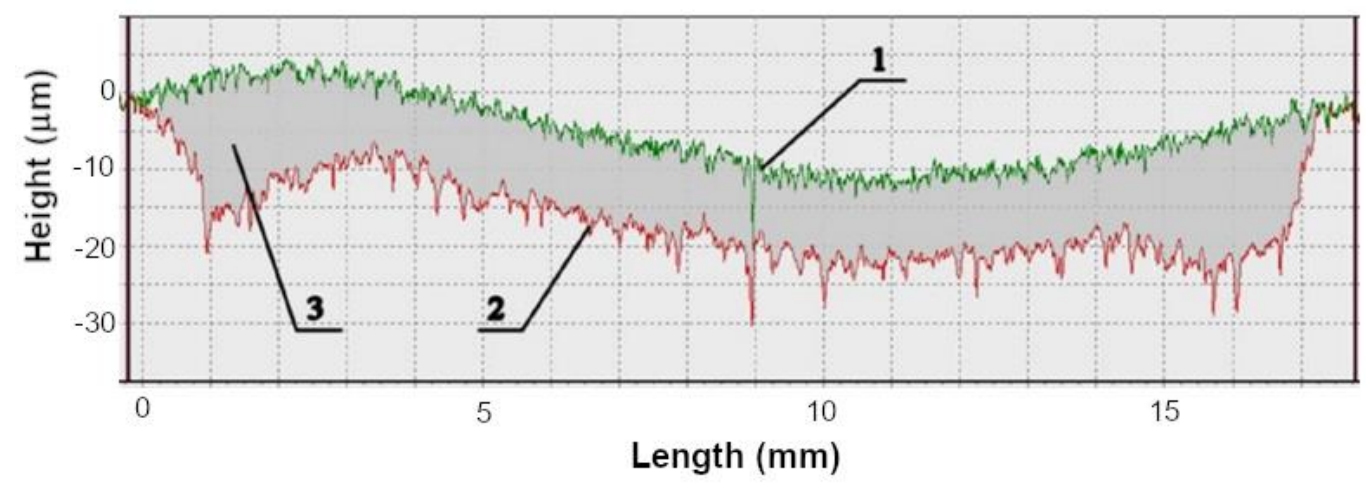

Fig. 1. A scheme for cutter wear measurement: 1: the longitudinal profile of cutting edge of a sharp cutter with zero cutting distance; 2 : the longitudinal profile of cutting edge of a cutter with the analyzed cutting distance; 3: blade wear area 
The longitudinal profile was recorded using a skid-shaped measuring sensor (Mitutoyo Poland, Wrocław, Poland) of $3 \mathrm{~mm}$ in length, the $25^{\circ}$ angle, and nose radius of $25 \mu \mathrm{m}$. Moreover, to determine wear intensity on the clearance and rake faces for selected cases, the wear profile was determined perpendicular to the major cutting edge. This profile was recorded using a cone-shaped gauge stylus with the vertical (nose) angle of $20^{\circ}$ and nose radius of $25 \mu \mathrm{m}$. An example perpendicular profile of blade wear is presented in Fig. 2 .

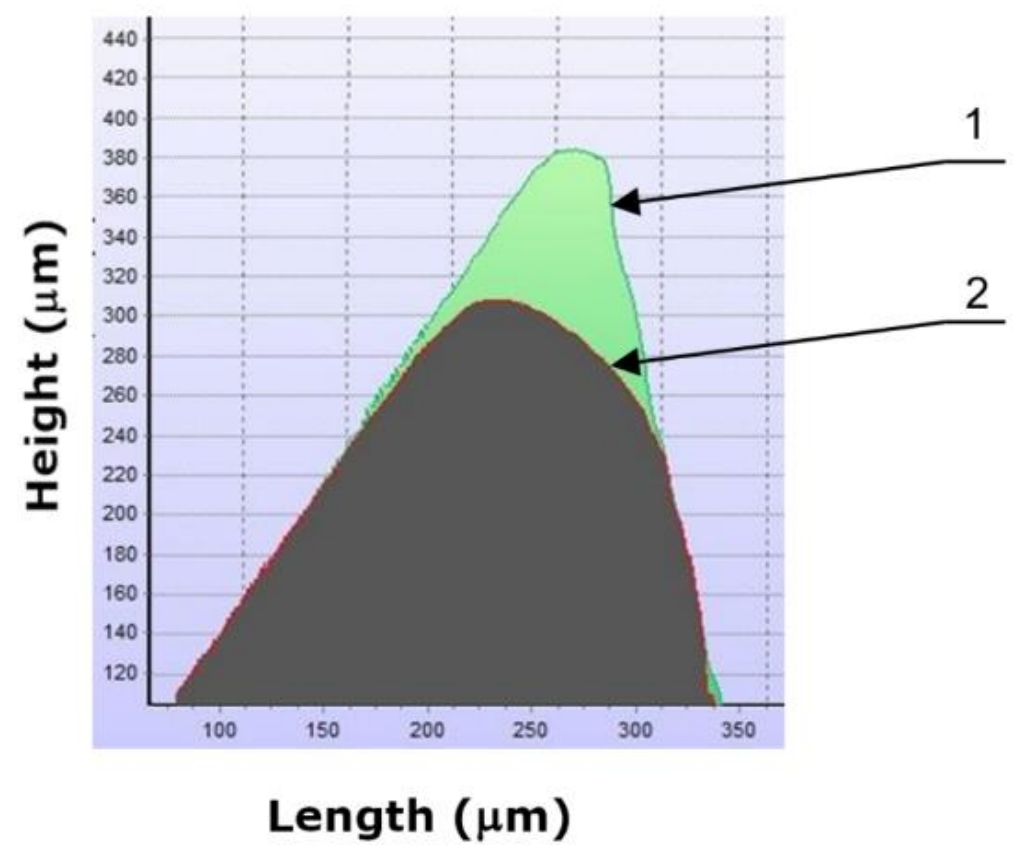

Fig. 2. Perpendicular profiles of cutter wear; 1 : the perpendicular profile of cutting edge of a sharp cutter with zero cutting distance; 2 : the perpendicular profile of cutting edge of a cutter with the analyzed cutting distance

Power measurements were taken using an N13 (Lumel S.A., Zielona Góra, Poland) energy parameter meter integrated with a USB-RS485 interface converter. Power was measured continuously for all milling processes.

Surface roughness was measured according to the ISO 4287 standard (1997). The $R$ a parameter, i.e., the arithmetic mean surface roughness, was adopted as a measure of surface roughness. The tests were conducted for a cut-off parameter of $2.5 \mathrm{~mm}$ and the stylus tip radius of $10 \mu \mathrm{m}$, stylus tip angle of $90^{\circ}$, detector measuring force of $0.75 \mathrm{mN}$, and feeding speed of $0.5 \mathrm{~mm} / \mathrm{s}$.

Blade wear and roughness were determined depending on blade type. For the HS cutter, measurement points were established after milling of 5, 10, 30, 50, and $75 \mathrm{~m}$, while for the HW cutter it was after 10, 50, 100, 150, 200, and $300 \mathrm{~m}$.

Statistical analysis was conducted in the Statistica 13 software (TIBCO Software Inc., Palo Alto, CA, USA), in which the analysis of variance was performed at the significance level $\mathrm{P}=0.05$, while the Duncan test was applied to determine significant differences between mean values. 


\section{RESULTS AND DISCUSSION}

Figure 3 presents the dependence of wear in tested cutters on the cutting path. For both the HS and the HW cutters, their blade wear increased with an increase in the cutting path. It needs to be stressed that Fig. 3 presents a 4-fold longer cutting path for the HW cutter. For the HS cutter the upward trend was exponential, while for the HW cutter this increase was linear. The trend lines describing this dependence were characterized by high goodness of fit to the data, as indicated by values of the coefficients of determination $\mathrm{R}^{2}$ exceeding 0.95 .
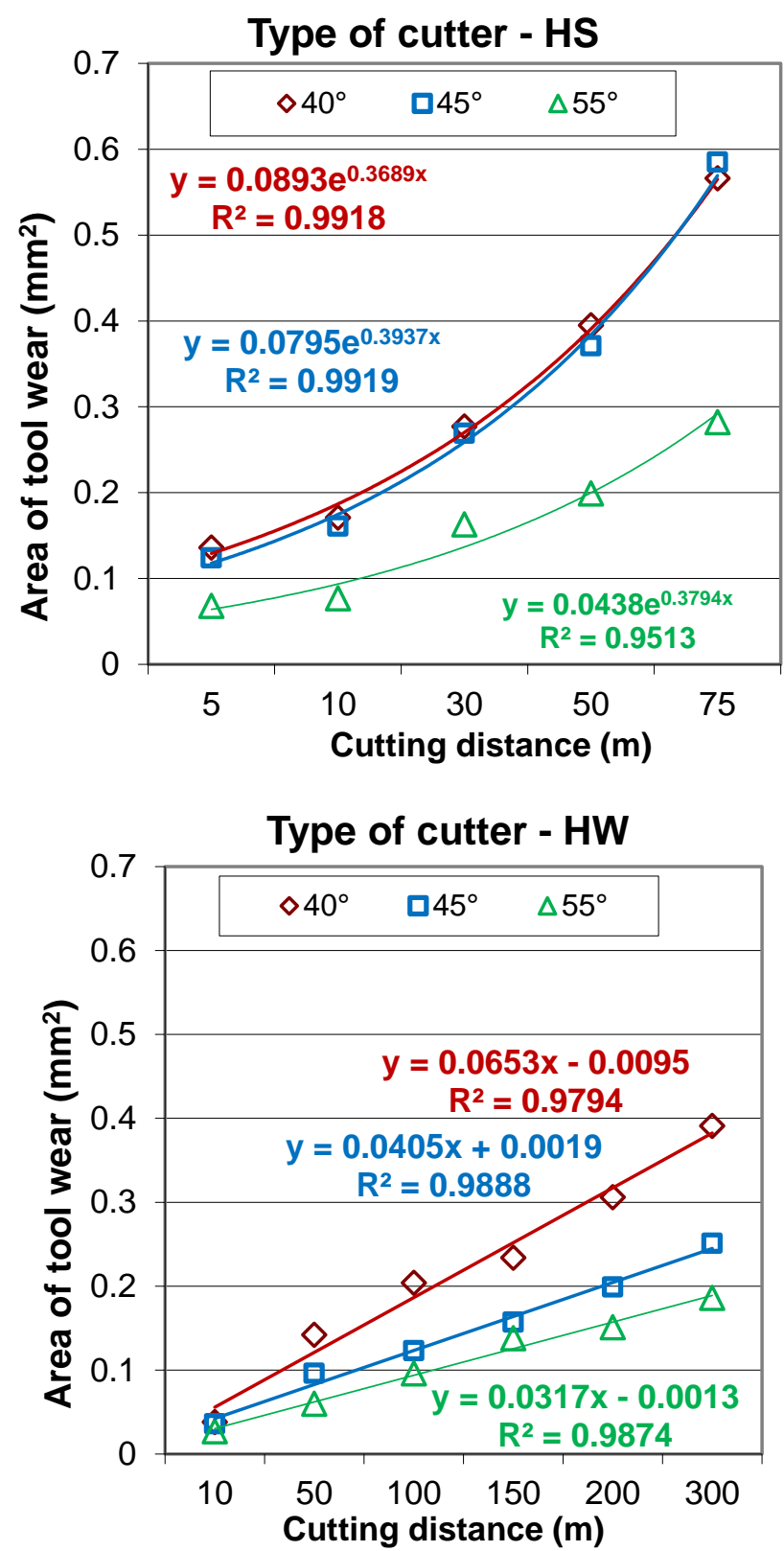

Fig. 3. The dependence of wear on cutting path for all analyzed cutter types 
For the HS cutters, similar wear was observed for the sharpness angles of $40^{\circ}$ and $45^{\circ}$, whereas for the $55^{\circ}$ cutter a markedly lesser wear was observed. For the final measurement point it was almost 2-fold lower than for the other sharpness angles. A greater variation in wear was recorded in the HW cutter, for which the highest values were found for the cutter with the $40^{\circ}$ angle, followed by $45^{\circ}$, while wear was smallest for the $55^{\circ}$ cutter. An increase in blade wear with an increase in the cutting path was reported by other authors (Kowaluk et al. 2009). In terms of wear, the HW cutters showed an approximately 5-fold lesser wear compared to the HS cutters at the same cutting path.

Figure 4 presents an example graph of wear for one of the analyzed blades. The plot is for the $40^{\circ} \mathrm{HS}$ cutter and was recorded for the maximum analysed cutting path of $75 \mathrm{~m}$. It is clear from the graph that blade wear at the panel faces is much greater than at the panel core. Such a variation in wear is caused by the greater density of faces in the MDF panels. Such a variation in machinability of MDF panels of various densities has been confirmed by other authors (Lin et al. 2006).

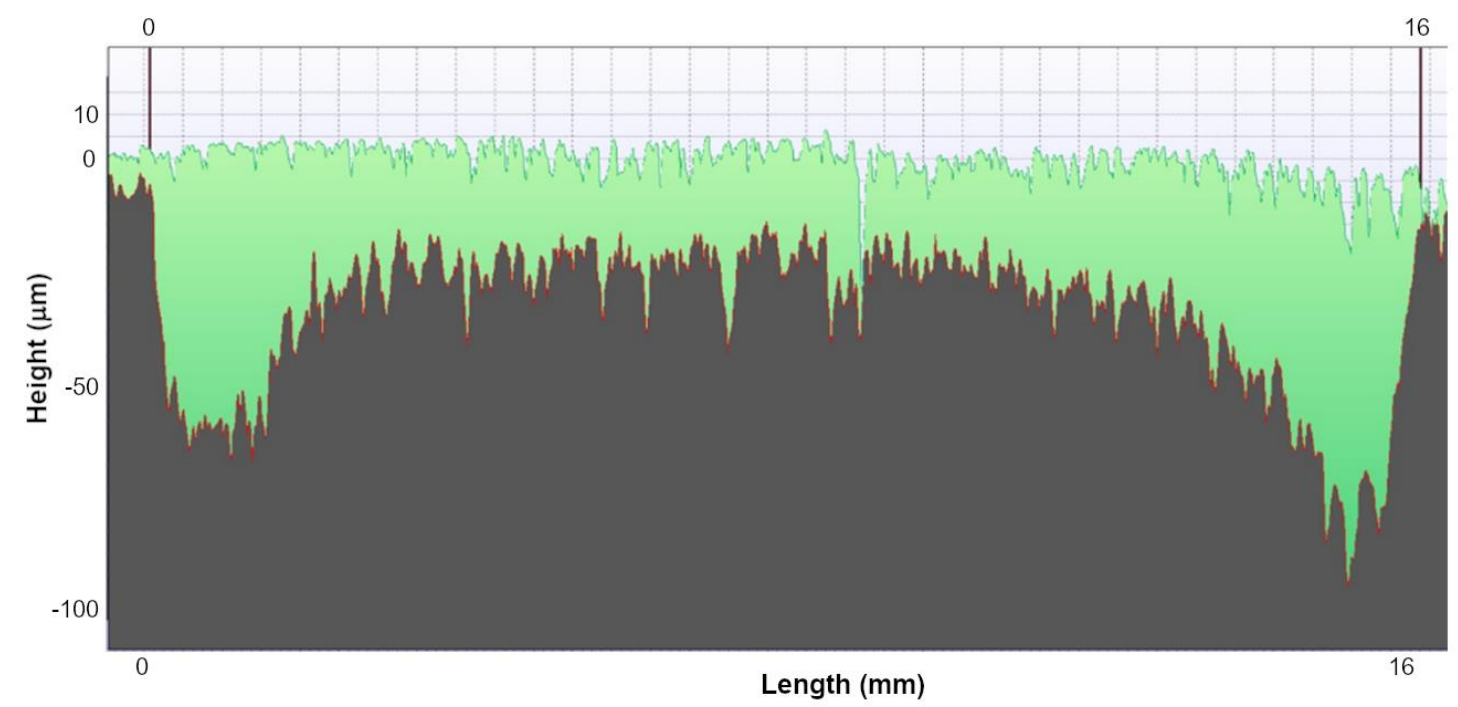

Fig. 4. A graph of blade wear in the HS $40^{\circ}$ cutter for the cutting path of $75 \mathrm{~m}$

Figure 5 presents changes in the cutting power for the HS cutter depending on the cutting path. Trend lines indicated the trend towards a linear growth for all the analyzed cases. Slopes of the lines for the established linear equations indicated the rate of changes for individual cutter angles. The most rapid increase in consumed energy was observed for the cutter with the smallest sharpness angle $\left(40^{\circ}\right)$, followed by the $45^{\circ}$ cutter, while the slowest increase was found for the cutter with the greatest sharpness angle. This may be explained by blade wear, which is presented in Fig. 3. Greater wear results in higher cutting resistance and consequently, a higher energy consumption. This was confirmed by other authors in their studies (Keturakis and Lisauskas 2010; Aguilera et al. 2016a).

Additionally, in Fig. 5 it may be observed that at cutting paths up to approximately $40 \mathrm{~m}$ the energy consumption was highest for the $55^{\circ}$ cutter, followed by those with $45^{\circ}$ and $40^{\circ}$ angles. The $55^{\circ}$ cutter had the highest cutting resistances. A less acute given angle resulted in smaller resistance. For the cutting path of approximately $40 \mathrm{~m}$, energy consumption was comparable for all the cutter angle variants. At the cutting path longer than approximately $40 \mathrm{~m}$ this trend was reversed, which may be explained by a slower wear of cutters with bigger angles. 


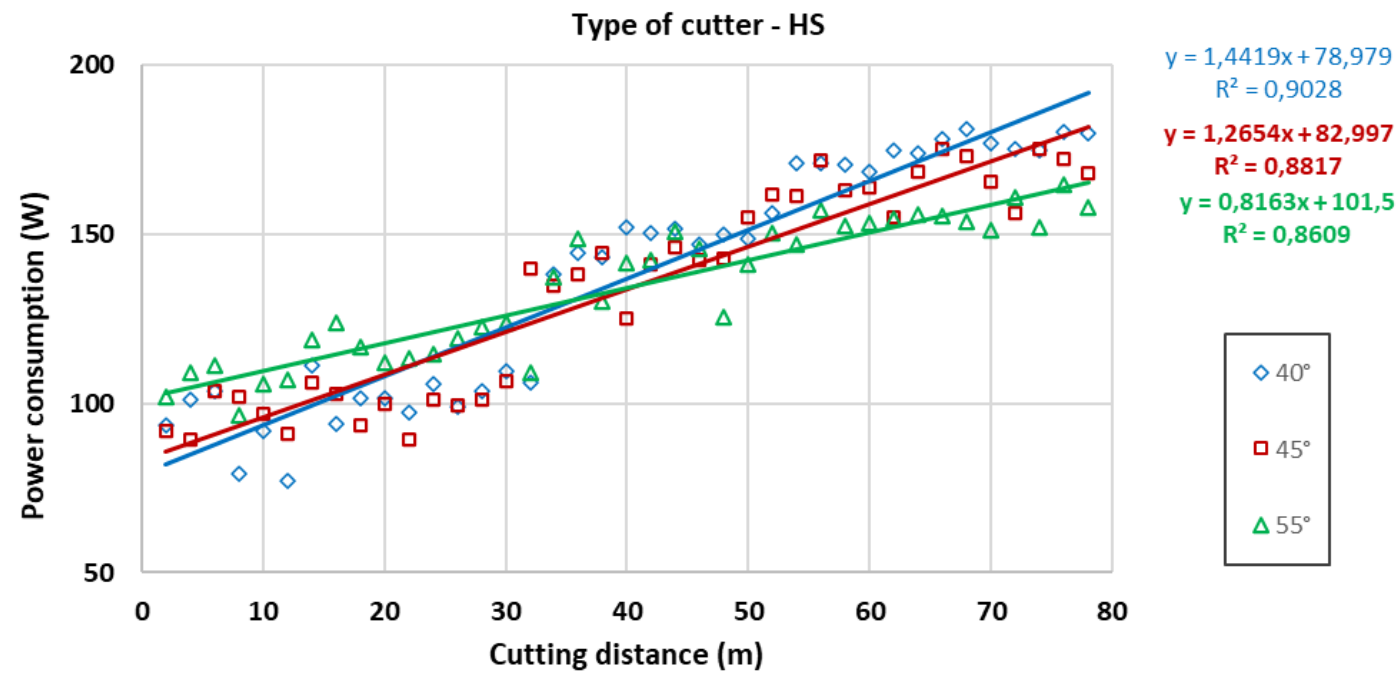

Fig. 5. The dependence of cutting power on cutting path for HS cutters

Figure 6 presents an analogous dependence for the HW cutter. The greatest energy consumption was recorded for the $55^{\circ}$ cutter, followed by the $45^{\circ}$ and the $40^{\circ}$ cutters. At the initial cutting phase, the energy consumption for the $55^{\circ}$ cutter was approximately $25 \%$ greater than that for the $45^{\circ}$ cutter and approximately $35 \%$ compared to the $40^{\circ}$ cutter. At the final measurement point $(300 \mathrm{~m})$, the energy consumption for the $55^{\circ}$ cutter was approximately $10 \%$ greater than that for the $45^{\circ}$ cutter and approximately $14 \%$ compared to the $40^{\circ}$ cutter. Slopes of the lines for the simple equations define the rate of increase in consumed energy. Trend lines indicate the trend towards a linear growth for all the analyzed cases, as was the HS cutter. However, for the harder HW cutter, because of lesser wear, the point of intersection of the trend lines was found outside the analyzed range of cutting paths. Based on the slopes of the trend lines determined for individual cases it was shown that the HW cutters exhibit an approximately 7-fold lower rate of cutting power increase when compared to the HS cutters.

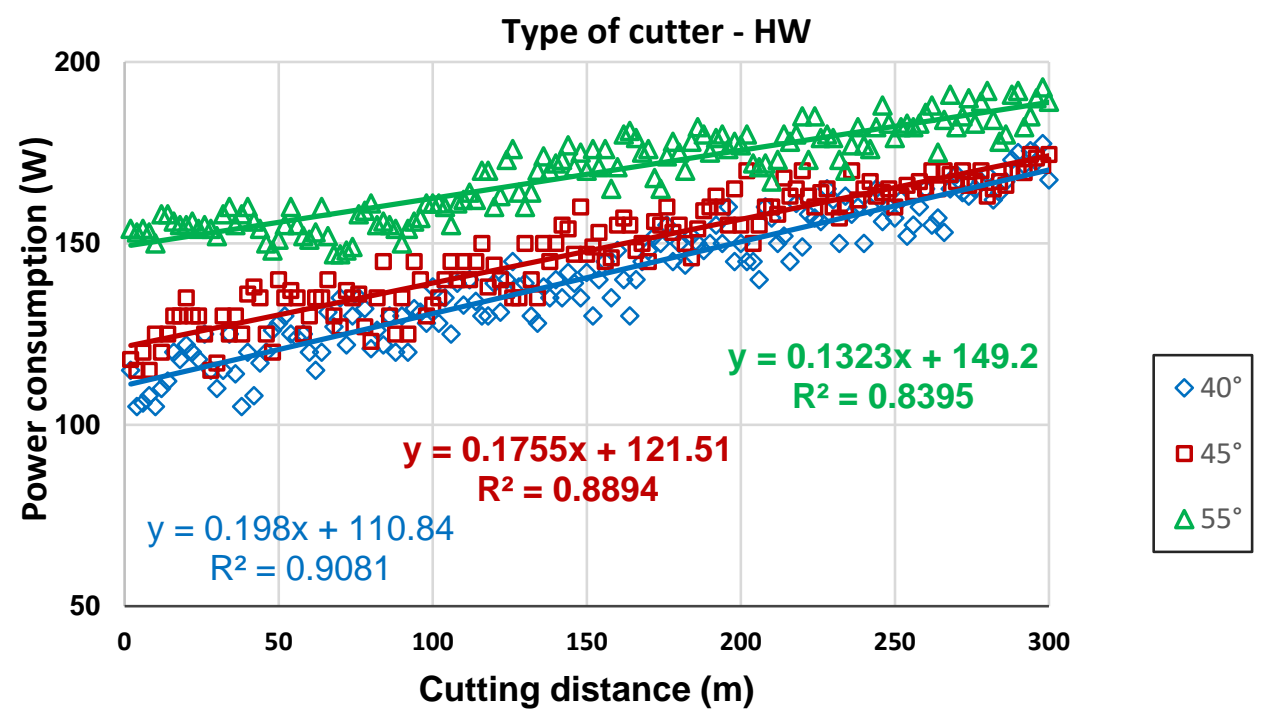

Fig. 6. The dependence of cutting power on cutting path for HW cutters 
Figure 7 presents perpendicular profiles established for the $45^{\circ} \mathrm{HS}$ and $\mathrm{HW}$ cutters for three selected variants of cutting path. For the HS cutters it was 30, 50, and $75 \mathrm{~m}$, while for the HW cutter it was 50, 200, and $300 \mathrm{~m}$, respectively.
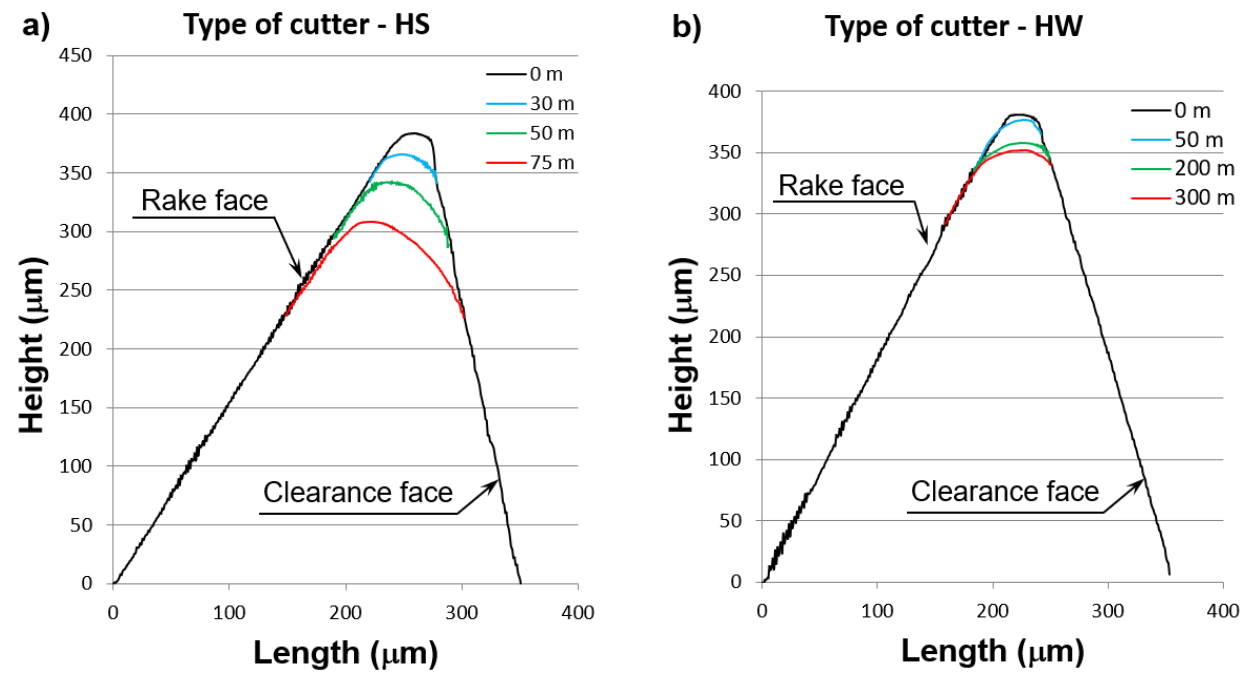

Fig. 7. Perpendicular profiles of blade wear in $45^{\circ}$ cutters for: a) HS and b) HW

Perpendicular profiles reflect the cutter blade wear both on the rake and clearance faces. For the HS cutter, a markedly greater blade wear was evident on the clearance face, which was generated because of friction of the cutter on the cut material. For the HW cutter, an increase in the nose radius of the cutting edge may be observed at a lack of a marked variation in wear on the clearance and rake faces, as it was the case in the HS cutter. Moreover, the profiles presented in Fig. 7 show greater wear of the HS cutter compared to the HW cutter, which resulted from the characteristics of the applied tool materials.

Table 3 presents results of analysis of variance (ANOVA) for the $R$ a parameter of surface roughness. The analysis was conducted at the significance level $\mathrm{P}=0.05$. It results from the data contained in this table that between the main factors, i.e., cutter type and angle, as well as the measurement point, there were statistically significant differences in mean values. In the analysis of second-order interactions, no differences were found between the sharpness angle and the measurement point $(\mathrm{P}>0.05)$.

Table 3. Results of the ANOVA for the Ra Parameter

\begin{tabular}{|c|c|c|c|c|c|}
\hline Effect & $\begin{array}{c}\text { Sum } \\
\text { Square }\end{array}$ & $\begin{array}{c}\text { Degrees } \\
\text { of } \\
\text { Freedom }\end{array}$ & $\begin{array}{c}\text { Mean } \\
\text { Square }\end{array}$ & $\begin{array}{c}\text { Fisher's } \\
\text { Test }\end{array}$ & $\mathbf{p}$ \\
\hline Intercept & 51590.37 & 1 & 51590.37 & 14136.79 & 0.000000 \\
\hline Cutter type (a) & 404.78 & 1 & 404.78 & 110.92 & 0.000000 \\
\hline Measuring location (b) & 4710.24 & 2 & 2355.12 & 645.35 & 0.000000 \\
\hline Sharpness angle (c) & 237.85 & 2 & 118.92 & 32.59 & 0.000000 \\
\hline $\mathrm{a} \times \mathrm{b}$ & 49.06 & 2 & 24.53 & 6.72 & 0.001354 \\
\hline $\mathrm{a} \times \mathrm{c}$ & 18.28 & 2 & 9.14 & 2.51 & 0.043014 \\
\hline $\mathrm{b} \times \mathrm{c}$ & 26.22 & 4 & 6.56 & 1.80 & 0.128820 \\
\hline $\mathrm{a} \times \mathrm{b} \times \mathrm{c}$ & 45.93 & 4 & 11.48 & 3.15 & 0.014533 \\
\hline Error & 1379.46 & 378 & 3.65 & & \\
\hline
\end{tabular}


In Table 4, homogeneous groups for the main factors were established using the Duncan test. It may be observed that for the cutter type and sharpness angle, significant differences were found between all the means. In the case of the measurement point, differences were recorded only between the panel core of lesser density and the pane faces of greater density. No significant differences were found in values of $R_{\mathrm{a}}$ for either panel face despite the slight variation in density of these layers. For the HW cutter, the MDF panel surface roughness was on average approximately $20 \%$ greater than for the HS cutter. Depending on the measurement point, the highest $R_{\mathrm{a}}$ values were recorded for the MDF core and they were on average approximately $80 \%$ higher than the means for the panel faces. The lowest $R_{\mathrm{a}}$ values depending on the cutter angle were observed for $45^{\circ}$, they were $13 \%$ higher for $55^{\circ}$ and by $18 \%$ higher for $40^{\circ}$, respectively.

Table 4. Means of $R_{a}$ for the Main Factors

\begin{tabular}{|c|c|c|c|c|c|c|c|c|}
\hline \multirow{2}{*}{$\begin{array}{c}\text { Roughness } \\
(\mu \mathrm{m})\end{array}$} & \multicolumn{2}{|c|}{ Cutter Type } & \multicolumn{3}{|c|}{ Measuring Location } & \multicolumn{3}{c|}{ Sharpness Angle $\left(^{\circ}\right)$} \\
\cline { 2 - 8 } & $\mathrm{HS}$ & $\mathrm{HW}$ & 1 & 2 & 3 & 40 & 45 & 55 \\
\hline$R_{\mathrm{a}}$ & $10.45^{\mathrm{a}}$ & $12.48^{\mathrm{b}}$ & $9.03^{\mathrm{a}}$ & $16.47^{\mathrm{b}}$ & $9.16^{\mathrm{a}}$ & $12.35^{\mathrm{a}}$ & $10.47^{\mathrm{b}}$ & $11.85^{\mathrm{c}}$ \\
\hline
\end{tabular}

Note: Letters $\left({ }^{\mathrm{a}},{ }^{\mathrm{b}},{ }^{\mathrm{c}}\right)$ next to averages mean homogeneous groups, if letters for samples are the same, it means that there were no statistically significant differences between these groups.

For the second-order analysis of variance, the results of interactions between the cutter type and measurement point, as well as the cutter type and cutter angle, are presented in Table 5. For the cutter type and measurement point, all the means differed significantly. However, the greatest variation was observed for roughness between the panel core and the panel faces, and this was regardless of the cutter type.

Table 5. Means for the (Second-order) Interactions between Cutter Type and Angle as Well as Cutter Type and Measurement Point

\begin{tabular}{|c|c|c|c|c|}
\hline Cutter Type & $\begin{array}{c}\text { Measuring } \\
\text { Location }\end{array}$ & $\boldsymbol{R}_{\mathbf{a}}(\boldsymbol{\mu m})$ & Sharpness Angle $\left(^{\circ}\right)$ & $\mathbf{R a}(\boldsymbol{\mu m})$ \\
\hline \multirow{3}{*}{$\mathrm{HS}$} & 1 & $8.46^{\mathrm{b}}$ & 40 & $11.14^{\mathrm{a}}$ \\
\cline { 2 - 5 } & 2 & $15.09^{\mathrm{e}}$ & 45 & $9.68^{\mathrm{c}}$ \\
\cline { 2 - 5 } & 3 & $7.78^{\mathrm{a}}$ & 55 & $10.52^{\mathrm{a}}$ \\
\hline \multirow{3}{*}{$\mathrm{HW}$} & 1 & $9.49^{\mathrm{c}}$ & 40 & $13.36^{\mathrm{b}}$ \\
\cline { 2 - 5 } & 2 & $17.63^{\mathrm{f}}$ & 45 & $11.12^{\mathrm{a}}$ \\
\cline { 2 - 5 } & 3 & $10.31^{\mathrm{d}}$ & 55 & $12.95^{\mathrm{b}}$ \\
\hline
\end{tabular}

Note: Letters $\left({ }^{a},{ }^{b},{ }^{c}\right)$ next to averages mean homogeneous groups, if letters for samples are the same, it means that there were no statistically significant differences between these groups.

For the interactions between the cutter type and angle, the lowest $R_{\mathrm{a}}$ values were recorded for the $45^{\circ}$ cutter, both for the HS and the HW cutters. For the HS cutter, the mean

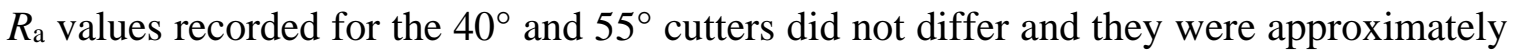
$12 \%$ higher than $R$ a for the $45^{\circ}$ cutter. A similar dependence was observed for the HW cutter. For the $40^{\circ}$ and $55^{\circ}$ angles the $R$ a values were on average approximately $18 \%$ higher compared to $R$ a for the $45^{\circ}$ cutter angle.

Figure 8 presents changes in the $R$ a parameter depending on all the analyzed factors, i.e., cutter type and angle as well as the measurement point. 

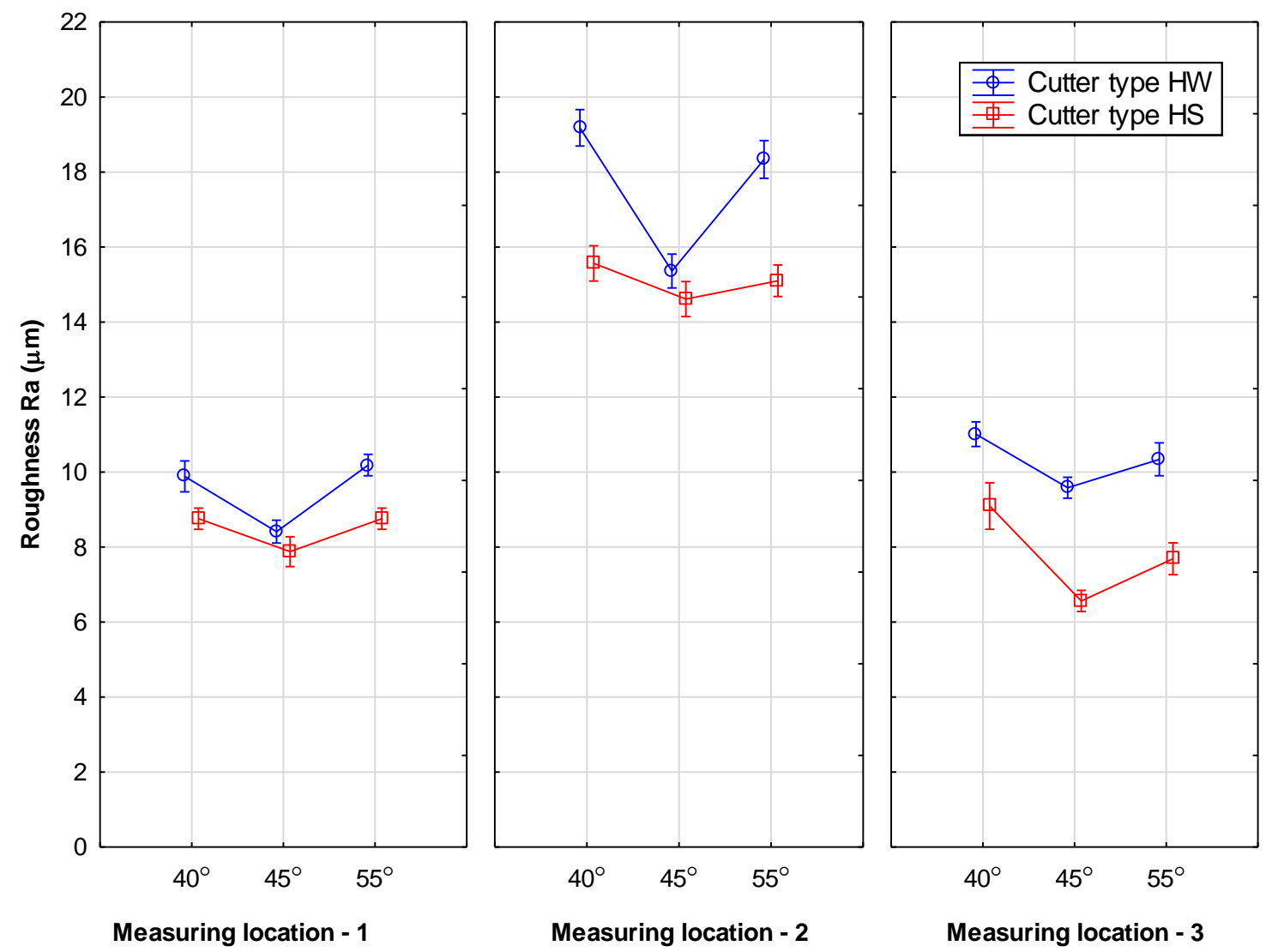

Fig. 8. Changes in $R_{a}$ depending on measurement point on MDF panel and on cutter type and angle

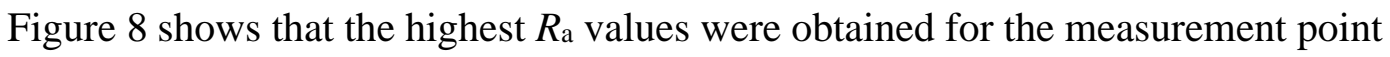
in the center of the panel, for the cutter angle of $40^{\circ}$ and for the HW cutter, while the lowest values were observed for the $45^{\circ}$ angle, the HS cutter and the back face of the MDF panel. Moreover, it was evident that high roughness was generated at the panel core regardless of the cutter angle and cutter type.

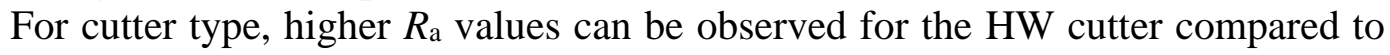
the HS cutter. For cutter angle, the lowest roughness values were obtained for the $45^{\circ}$ cutter.

Figure 9 presents changes in $R_{\mathrm{a}}$ depending on blade wear generated after a specific cutting path. For all the cutter types and sharpness angles an upward trend was observed. The increase in surface roughness of lignocellulose materials occurs because of tool wear, which has been confirmed in numerous studies (Keturakis and Juodeikienè 2007; Aguilera et al. 2016b).

The established trend lines confirm the linear character of this increase with high coefficients of determination. Based on values of these coefficients, it may be stated that machining with a $55^{\circ}$ cutter results in the greatest scatter of results, while it is lowest for the $40^{\circ}$ cutter. 


\section{HS}

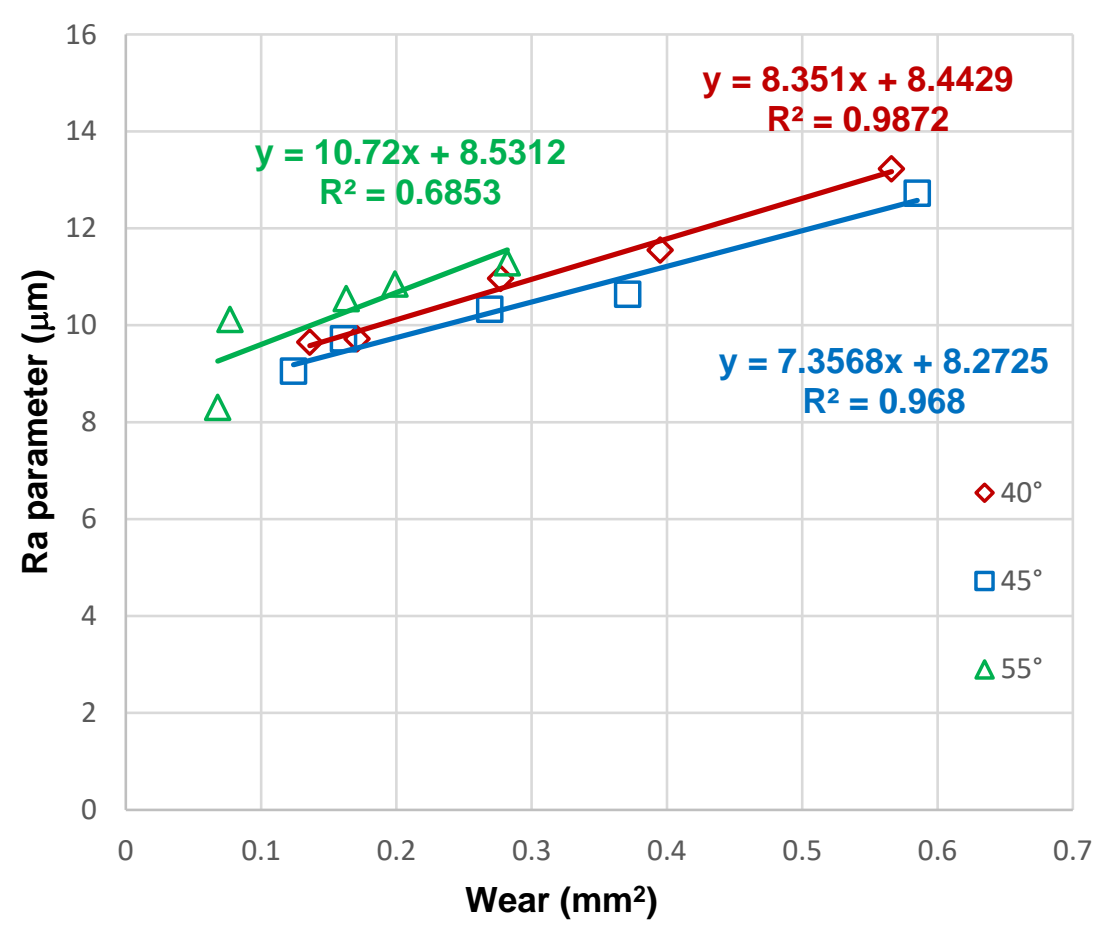

HW

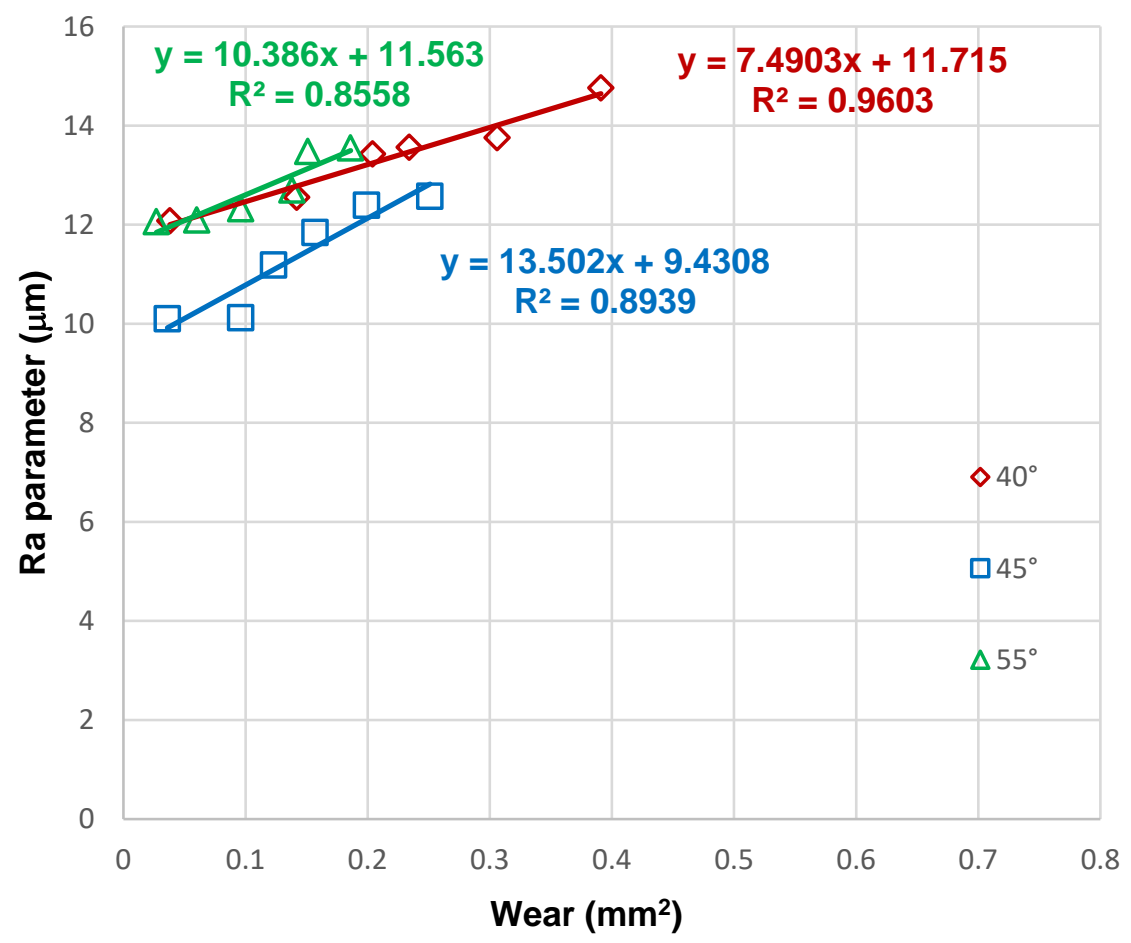

Fig. 9. Changes in $R_{\mathrm{a}}$ depending on cutter wear 


\section{CONCLUSIONS}

1. Results of the conducted tests showed the effect of angles and types of cutter blades on their durability, roughness of the machined surface, and on the energy consumption during milling of MDF panels.

2. The smallest blade wear was observed for the cutters with the $55^{\circ}$ sharpness angle, while it was greatest for the $40^{\circ}$ angle. In terms of wear, the HW cutters showed an approximately 5-fold lower wear compared to the HS cutters at the same cutting path. For the analyzed cutting path variants, with an increase in their length the wear of HS cutter blades increased exponentially, while for the HW cutters this increase was linear. The intensity of this increase was dependent on the sharpness angle and it decreased with its increase. In the faces of the MDF panel an increased wear of blades was observed because of the greater panel density in those layers.

3. Cutting power for the MDF panel increased with an increase in the cutting path and blade wear. An increase in the sharpness angle caused a slower increase in the consumption of cutting power. The blade material is of considerable importance for the increase in milling power. The greatest increment in power was recorded for the HS cutters, while it was lowest for the HW cutters. Based on the slopes of the trend lines established for individual tested variants, the HW cutters show an approximately 7-fold lesser rate of increase in cutting power consumption when compared to the HS cutters.

4. Based on the established perpendicular profiles of cutter blade wear, a more intensive wear of the HS cutters was recorded on the clearance face, while for the HW cutter no marked variation was observed for wear on the clearance and rake faces.

5. Surface roughness specified by $R_{\mathrm{a}}$ showed variation depending on all the analyzed factors. For the HW cutter, roughness compared with the HS cutter was on average $20 \%$ higher. The MDF core showed on average an $80 \%$ higher roughness in relation to the panel faces, which was caused by the greater density of those layers. The lowest roughness was obtained for the cutters with the $45^{\circ}$ sharpness angle.

6. The change in surface roughness caused by blade wear showed an upward trend, with the lowest roughness among the three analysed angles observed for the $45^{\circ}$ cutter angle.

7. Considering the effect of all the analyzed factors, the HW cutter with the $45^{\circ}$ angle may be proposed as optimal, because it showed a relatively low wear and cutting power while providing good quality of the milled surface.

\section{ACKNOWLEDGMENTS}

The paper was financed within the framework of Ministry of Science and Higher Education program 'Regional Initiative of Excellence' in years 2019 through 2022, Project No. 005/RID/2018/19. 


\section{REFERENCES CITED}

Aguilera, A., Meausoone, P. J., and Martin, P. (2000). "Wood material influence in routing operations: The MDF case," Holz als Roh-und Werkstoff 58(4), 278-283. DOI: $10.1007 / \mathrm{s} 001070050425$

Aguilera, A., Méausoone, P. J., Rolleri, A., Barros, J. L., Burgos, F., and Aguilar, C. (2016a). "Advances on indirect methods to evaluate tool wear for radiata pine solid wood moulding," Wear 350-351, 27-34. DOI: 10.1016/j.wear.2015.12.011

Aguilera, A., Rolleri, A., and Burgos, F. (2016b). "Cutting distance as factor to evaluate the quality of wood machined surfaces: A preliminary study," Maderas. Ciencia y Tecnología 18(1), 3-18. DOI: 10.4067/S0718-221X2016005000001

Atanasov, V., and Kovatchev, G. (2019). "Determination of the cutting power during milling of wood-based materials," Acta Facultatis Xylologiae Zvolen 61(1), 93-101. DOI: 10.17423/afx.2019.61.1.09

Davim, J. P., Clemente, V. C., and Silva, S. (2009). "Surface roughness aspects in milling MDF (medium density fibreboard)," The International Journal of Advanced Manufacturing Technology 40, 49-55. DOI: 10.1007/s00170-007-1318-z

Deus, P. R., Alves, M. C., and Vieira, F. H. A. (2015). “The quality of MDF workpieces machined in CNC milling machine in cutting speeds, feedrate, and depth of cut," Meccanica 50(12), 2899-2906. DOI: 10.1007/s11012-015-0187-z

Deus, P. R., Alves, M. C. S., Vieira, F. H. A., and Bilesky, L. R. (2018). "Analysis of the cutting parameters in front milling for medium density fiberboard," BioResources 13(2), 3404-3410. DOI: 10.15376/biores.13.2.3404-3410

Hiziroglu, S., and Kosonkorn, P. (2006). "Evaluation of surface roughness of Thai medium density fiberboard (MDF)," Building and Environment 41(4), 527-533. DOI: 10.1016/j.buildenv.2005.02.016

Hiziroglu, S., Jarusombuti, S., and Fueangvivat, V. (2004). "Surface characteristics of wood composites manufactured in Thailand," Building and Environment 39(11), 1359-1364. DOI: 10.1016/j.buildenv.2004.02.004

İşleyen, Ü. K., and Karamanoğlu, M. (2019). "The influence of machining parameters on surface roughness of MDF in milling operation," BioResources 14(2), 3266-3277. DOI: $10.15376 /$ biores. 14.2.3266-3277

ISO 4287 (1997). "Geometrical product specifications (GPS) -- Surface texture: Profile method -- Terms, definitions and surface texture parameters," International Organization for Standardization, Geneva, Switzerland.

Kazlauskas, D., Jankauskas, V., and Keturakis, G. (2019). "Research on durability of AlCrN coated tungsten carbide (WC-Co) cutters during oak wood milling," in: Proceedings of BALTTRIB'2019, J. Padgurskas (ed.), Vytautas Magnus University, Kaunas, Lithuania, pp. 243-249.

Keturakis, G., and Juodeikienè, I. (2007). "Investigation of milled wood surface roughness," Technologija 13(1), 47-51.

Keturakis, G., and Lisauskas, V. (2010). "Influence of the sharpness angle on the initial wear of the wood milling knives," Materials Science 16(3), 205-209.

Koleda, P., Barcík, Š., Svoreň, J., Naščák, L., and Dobrík, A. (2019). "Influence of cutting wedge treatment on cutting power, machined surface quality, and cutting edge wear when plane milling oak wood," BioResources 14(4), 9271-9286. DOI: 10.15376/biores.14.4.9271-9286 
Kowaluk, G., Szymanski, W., Palubicki, B., and Beer, P. (2009). "Examination of tools of different materials edge geometry for MDF milling," European Journal of Wood and Wood Products 67(2), 173-176. DOI: 10.1007/s00107-008-0302-0

Lin, R. J., Van Houts, J., and Bhattacharyya, D. (2006). "Machinability investigation of medium-density fibreboard," Holzforschung 60(1), 71-77. DOI: 10.1515/HF.2006.013

Pinkowski, G., Szymański, W., Krauss, A., and Stefanowski S. (2018). "Effect of sharpness angle and feeding speed on the surface roughness during milling of various wood species," BioResources 13(3), 6952-6962. DOI: 10.15376/biores.13.3. 69526962

Pinkowski, G., Szymański, W., Gilewicz, A., and Sydor, M. (2015). "Wear of cemented carbide cutters after milling of MDF boards," Forestry and Wood Technology 90, 143-148.

Sedlecký, M. (2017). "Surface roughness of medium-density fiberboard (MDF) and edge-glued panel (EGP) after edge milling," BioResources 12(4), 8119-8133. DOI: 10.15376/biores.12.4.8119-8133

Sedlecký, M., and Kvietková, M. S. (2017). "Surface waviness of medium density fiberboard and edge-glued panel after edge milling," Wood Research 62(3), 459-470.

Sedlecký, M., Kvietková, M. S., and Kminiak, R. (2018a). "Medium-density fiberboard (MDF) and edge-glued panels (EGP) after edge milling-surface roughness after machining with different parameters," BioResources 13(1), 2005-2021. DOI: 10.15376/biores.13.1.2005-2021

Sedlecký, M., Kvietková, M. S., Kminiak, R., and Kaplan, L. (2018b). "Medium-density fiberboard and edge-glued panel after edge milling-surface waviness after machining with different parameters measured by contact and contactless method," Wood Research 63(4), 683-698.

Souza, A. J., Jeremias, T. D., Gonzalez, A. R., and Amorim, H. J. (2019). “Assessment of melamine-coated MDF surface finish after peripheral milling under different cutting conditions," European Journal of Wood and Wood Products 77(4), 559-568. DOI: 10.1007/s00107-019-01413-y

Stefanowski, S., Frayssinhes, R., Pinkowski, G., and Denaud, L. (2020). "Study on the in-process measurements of the surface roughness of Douglas fir green veneers with the use of laser profilometer," European Journal of Wood and Wood Products 78(3), 555-564. DOI: 10.1007/s00107-020-01529-6

Sütcü, A., and Işleyan, Ü. K. (2012). "Effect of machining parameters on surface quality after face milling of MDF," Wood Research 57(2), 231-240.

Zhong, Z. W., Hiziroglu, S., and Chan, C. T. F. (2013). "Measurement of the surface roughness of wood-based materials used in furniture manufacture," Measurement 46(4), 1482-1487. DOI: 10.1016/j.measurement.2012.11.041

Article submitted: August 17, 2020; Peer review completed: November 15, 2020; Revised version received and accepted: November 18, 2020; Published: November 24, 2020.

DOI: 10.15376/biores.16.1.558-571 